DOI: $10.25178 /$ nit.2019.4.1

\title{
Калмыцкая терминология родства как отражение исторических связей и этнокультурных контактов Ойратского мира и тувинцев"
}

\author{
Владимир А. Попов \\ Санкт-Петербургский государственный университет; Институт восточных рукописей РАН, \\ Российская Федерация, \\ Алексей А. Бурыкин \\ Калмыцкий научный центр Российской академии наук, Российская Федерация
}

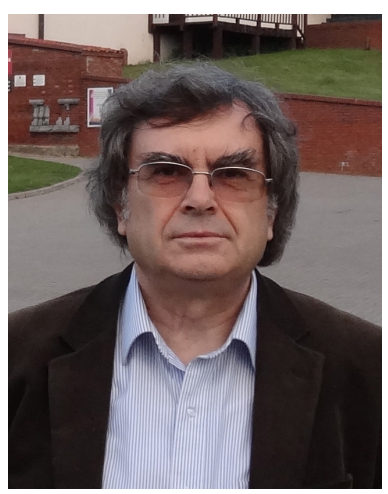

Статья представляет собой обобщающую работу, посвященную выявлению специфики системы терминов родства калмыков как лексической микросистемы в отношении распределения составляющих ее отдельных номинационных единии, а также тех семантических признаков, которые формируют лексические оппозиции внутри этой системы и определяют ее историкотипологическую динамику, в сравнении с системой терминов родства тувинцев. Объясняются причины сходств и различий между терминологиями родства монголоязычных (в частности, ойратских) и тюркоязычных народов на примере номенклатур родства калмыков и тувинцев, $а$ также рассматривается взаимодействие терминов родства и свойства тюркского и монгольского происхождения у тувинцев.

Отмечается, что объяснение наблюдаемых лексических сходств тюркских и монгольских языков исключительно как контактных явлений в свете фактов истории самих тюркских языков имеет на несколько порядков меньшую вероятность, чем объяснение тех же сходств как следствие генетического родства алтайских языков при наличии в них некоторого количества перекрестных заимствований. Терминология родства тувинцев-эрзинцев носит отчетливые следы языковых контактов смонголами-ойратами. Для системы терминов родства калмыков характерны строгая соотнесенность терминов родства по признаку пола как по восходящей, так и по нисходящей линиям, наличие особой лексической единицы для номинации родственников по материнской стороне, счет родства до 9-го поколения как по восходящей, так и по нисходящей линиям, тогда как у других монголоязычных народов учитывается счет родства только до 5-го поколения по восходящей и 4-го поколения по нисходящей линиям.

Ключевые слова: тувинцы; калмыки; Ойратский мир; терминология родства; компонентный анализ; этнокультурные контакты

Исследование проведено в рамках государственной субсидии - проект «Устное и письменное наследие монгольских народов России, Монголии и Китая: трансграничные традиции и взаимодействия» (регистрационный номер АAAA-A19-119011490036-1).

\section{Для цитирования:}

Попов В. А., Бурыкин А. А. Калмыцкая терминология родства как отражение исторических связей и этнокультурных контактов Ойратского мира и тувинцев [Электронный ресурс] // Новые исследования Тувы. 2019, № 4. URL: https://nit.tuva.asia/nit/article/view/877 (дата обращения: дд.мм.гг.). DOI: 10.25178/nit.2019.4.1

Попов Владимир Александрович - доктор исторических наук, профессор кафедры этнографии и антропологии Института истории Санкт-Петербургского государственного университета; главный научный сотрудник отдела Ближнего и Среднего Востока Института восточных рукописей РАН. Адрес: 199034, Россия, г. Санкт-Петербург, Университетская наб, д. 7-9. Тел.: +7 (921) 633-84-34. Эл. адрес: v.a.popov@spbu.ru; popoffwladimir@gmail.com ORCID ID: 0000-0002-9289-6443

Бурыкин Алексей Алексеевич - доктор филологических наук, доктор исторических наук, ведущий научный сотрудник отдела монгольской филологии Калмыцкого научного центра РАН. Адрес: 358000, Россия, г. Элиста, ул. И. К. Илишкина, д. 8. Тел.: +7 (911) 709-14-76. Эл. адрес: albury@mail.ru ORCID ID: 0000-0002-9119-2698

Popov Vladimir Aleksandrovich, Doctor of History, Professor, Department of Ethnography and Anthropology, Institute of History, St. Petersburg State University; Chief Researcher, Department of Near Eastern and Middle Eastern Studies, Institute of Oriental Manuscripts of the RAS. Postal address: 199034, Russian Federation, St. Petersburg, Universitetskaya nab. 7-9. Tel.: +7 (921) 633-84-34. E-mail: v.a.popov@spbu.ru; popoffwladimir@gmail.com

Burykin Aleksey Alekseevich, Doctor of Philology, Doctor of History, Leading Research Associate, Department of Mongolian Philology, Kalmyk Scientific Center of the Russian Academy of Sciences. Postal address: 8 Ilishkin St., 358000 Elista, Russian Federation. Tel.:

+7 (911) 709-14-76. E-mail: albury@mail.ru 


\title{
Kalmyk kinship terminology as a reflection of historical ties and ethnocultural contacts between the Oirat world and Tuvans
}

\author{
Vladimir A. Popov \\ St. Petersburg State University; Institute of Oriental Manuscripts of the RAS, Russian Federation, \\ Alexey A. Burykin \\ Kalmyk Scientific Center of the Russian Academy of Sciences, Russian Federation
}

\begin{abstract}
The article is a summarizing work identifying the specificity of the Kalmyk system of kinship terms as a lexical microsystem in relation to the distribution of its individual nominal units, as well as those semantic features that form lexical oppositions within this system and determine its historical and typological dynamics, in comparison with the kinship terminology system of the Tuvans. The paper explains reasons for similarities and differences between kinship terms of Mongolic (namely, Oirat) and Turkic peoples through the examples of kinship relations inherent to the Kalmyks and Tuvans, and considers the interaction of terms denoting kinship and affinity of Turkic and Mongolic origin within Tuvan-language discourse.

It is noted that the explanation of the observed lexical similarities of the Turkic and Mongolic languages exclusively as contact phenomena in the light of facts from the history of Turkic languages as such is far less reliable than the explanation of the same similarities as a consequence of genetic relationship of the Altaic languages, though in the context of a certain number of crossborrowings. The kinship terminology of Erzin Tuvans contains distinct traces of language contacts with the Oirat-Mongols. The Kalmyk system of kinship terms is characterized by a strict correlation of kinship terms by gender both in ascending and descending lines, the presence of a special lexical unit for nominating maternal relatives, and kinship counting up to the 9th generation in both ascending and descending lines while other Mongolic peoples take into account the kinship only up to the 5th generation in the ascending line and the 4th generation in the descending line respectively.
\end{abstract}

Keywords: Tuvans; Kalmyks; Oirat world; kinship terminology; componential analysis; ethnocultural contacts

"The reported study was funded by government subsidy - project name 'Oral and Written Heritage of the Mongolic Peoples of Russia, Mongolia and China: Cross-Border Traditions and Interactions' (registration number AAAA-A19-119011490036-1).

\section{For citation:}

Popov V. A. and Burykin A. A. Kalmyk kinship terminology as a reflection of historical ties and ethnocultural contacts between the Oirat world and Tuvans. The New Research of Tuva. 2019, no. 4. URL: https://nit.tuva.asia/nit/article/ view/877 (access date ... ). DOI: 10.25178/nit.2019.4.1

\section{Введение}

Настоящая статья представляет собой обобщающую работу, посвященную выявлению специфики системы терминов родства (СТР) калмыков как лексической микросистемы в отношении распределения составляющих ее отдельных номинационных единиц, а также тех семантических признаков, которые формируют лексические оппозиции внутри СТР и определяют ее историко-типологическую динамику, в сравнении с СТР тувинцев. Такой подход позволит не только поставить вопрос о реконструкции общемонгольской СТР, но и объяснить причины сходств и различий между СТР монголоязычных (в частности, ойратских) и тюркоязычных народов на примере СТР калмыков и тувинцев, а также рассмотреть взаимодействие СТР тюркского и монгольского происхождения у тувинцев. В свою очередь, это позволит определить, в какой мере СТР отражают ареальные контакты и исторические связи Ойратского мира ${ }^{1}$, а в какой являются следствием генетического родства тюркских и монгольских языков.

Нет необходимости давать здесь полный список терминов родства (ТР) и терминов свойства (ТС) и описывать все детали СТР калмыков (тем более, что это уже сделано в ряде публикаций одного из соавторов (см.: Омакаева, Бурыкин, 1999, 2007). Достаточно только охарактеризовать самые главные ее особенности, показать ее сходства и отличия от СТР других монголоязычных народов, а также сопоставить ее с тувинской номенклатурой родства. История исследования тувинской терминологии

${ }^{1}$ Под Ойратским миром мы вслед за другими исследователями понимаем потомков ойратов - калмыков России, ойратов Монголии и Китая. 
родства подробнейшим образом описана в специальной статье (Шалык, 2018: Электр. ресурс), историческая ретроспектива изучения калмыцкой СТР описана одним из авторов (Омакаева, Бурыкин, 2001, 2007).

Лексический материал, которым оперируют авторы, выбран из наиболее полных из существующих калмыцко-русского и русско-калмыцкого словарей (Русско-калмыцкий словарь, 1964; Калмыцкорусский словарь, 1977), из наиболее авторитетных двуязычных словарей монгольских и тувинского языков (Тувинско-русский словарь, 1968; Lessing, 1960; Большой академический ... , 2001-2002), а также из ряда этнографических и лингвистических работ, в которых зафиксированы сведения по СТР тувинцев и калмыков, и представлен в соответствующих статьях (см., помимо указанных выше: Бурыкин, Летягина, 1999; Бурыкин, 1998; Омакаева, Бурыкин, 2001, 2007; Степанофф, 2009; Очирова, Омакаева, 2014; Мулаева, 2016), а также в публикациях (Номинханов, 1958, 1975; Корсункиев, 1977; Бембеев, 2004; Кара-оол, 2006; Биче-оол, 2001, 2018; Бакаева, 2014, 2016; Музраева, 2016). Материалы по терминологии родства письменного монгольского языка рассматривались по наиболее полному словарю Ф. Лессинга (Lessing, 1960).

\section{Калмыцкая терминология родства}

Компонентный анализ ${ }^{1}$ релевантных для наших целей ТР калмыков, охватывающих 5 поколений, позволяет выделить следующие дифференциальные переменные (см. табл. 1):

1. Генеалогическое поколение:

$1.1-+2$ поколение

$1.2-+1$ поколение

1.3 - 0 поколение

$1.4--1$ поколение

$1.5--2$ поколение

2. Пол альтера ${ }^{2}$ :

2.1 - мужской

2.2 - женский

3. Пол коннектора ${ }^{3}$ :

3.1 - мужской

3.2 - женский

4. Латеральность ${ }^{4}$ альтера:

4.1 - патрилатеральность

4.2 - матрилатеральность

5. Относительный возраст альтера:

5.1 - старше эго

5.2 - младше эго

\footnotetext{
${ }^{1}$ Компонентный анализ - один из наиболее эффективных методов исследования внутренней структуры СТР. Сущность компонентного анализа заключается в возможности расщепления значения на составляющие его компоненты, или дифференциальные переменные.

Основные понятия компонентного анализа следующие: 1) тип родства - отношение родства; 2) класс родства - термин родства, обозначающий данный тип родства; 3) денотат - тип родства определенного класса родства, то есть родственное отношение, обозначенное конкретным термином; 4) десигнат - совокупность денотатов; 5) сигнификат - совокупность компонентов (дифференциальных переменных) данного десигната.

Цель компонентного анализа состоит в нахождении сигнификатов, то есть он позволяет выявить основные структурообразующие компоненты СТР, а также дает возможность рассмотреть эволюцию СТР как трансформацию дифференциальных переменных (подробнее см.: Кузнецов, 1971; Крюков, 1972: 24-27; Членов, 1972; Попов, 1979).

${ }^{2}$ Альтер - родственник или свойственник эго (говорящего), определяемый тем или иным термином.

${ }^{3}$ Коннектор - посредник, связующий родственник, осуществляющий связь между эго и альтером.

${ }^{4}$ Латеральность - принцип различения двух категорий родственников индивида по сторонам (материнской и отцовской): матрилатераты - родственники со стороны матери, патрилатераты - родственники со стороны отца.
} 
Табл. 1. Компонентный анализ СТР калмыков ${ }^{1}$

Tab. 1. Componential analysis of Kalmyk system of kinship terms

\begin{tabular}{|c|c|c|c|c|c|c|}
\hline классы родства & десигнаты & \multicolumn{5}{|c|}{ сигнификаты } \\
\hline аав & РмP & 1.1 & 2.1 & - & - & - \\
\hline ээж & РжР & 1.1 & 2.2 & - & - & - \\
\hline эцк & Рм & 1.2 & 2.1 & - & 4.1 & - \\
\hline эк & Рж & 1.2 & 2.2 & - & 4.2 & - \\
\hline aвh & ДмРРм & 1.2 & 2.1 & 3.1 & 4.1 & - \\
\hline haha & ДжРРм & 1.2 & 2.2 & 3.2 & 4.1 & - \\
\hline $\mathrm{ax}$ & ДмРРж = +ДмР & - & 2.1 & - & - & 5.1 \\
\hline эгч & ДжРРж = +ДжР & - & 2.2 & - & - & 5.1 \\
\hline дү көвүн & -ДмР & 1.3 & 2.1 & - & - & 5.2 \\
\hline дү күүкн & -ДжР & 1.3 & 2.2 & - & - & 5.2 \\
\hline үй & ДДРРм & 1.3 & - & 3.1 & 4.1 & - \\
\hline бөл & ДДРРж & 1.3 & - & 3.2 & 4.2 & - \\
\hline көвүн & Дм & 1.4 & 2.1 & - & - & - \\
\hline күүкн & Дж & 1.4 & 2.2 & - & - & - \\
\hline ач & ДДм & 1.5 & - & 3.1 & - & - \\
\hline зе & ДДж & 1.5 & - & 3.2 & - & - \\
\hline
\end{tabular}

Отличительной особенностью СТР калмыков является строгая соотнесенность ТР по признаку пола альтера - она прослеживается как по восходящей, так и по нисходящей линиям. Эти отношения несколько затемнены только в ТР, обозначающих родственные отношения в +3 и -3 поколениях и далее по восходящей и нисходящей линиям. Однако этот материал фрагментарно представлен в имеющихся лексических и словарных источниках и требует дальнейшего изучения, в том числе дополнительной проверки с информантами, поскольку ТР, обозначающие прямых предков и потомков далее третьего поколения по нисходящей и восходящей линиям, в современном калмыцком языке почти не используются.

Заслуживает внимания также то, что в калмыцком, в отличие от других монгольских языков, названия младших сиблингов (-ДР) дифференцированы по признаку пола с помощью слов көвүн 'сын' (ДмР) и күүкн 'дочь' (ДжР), выступающих универсальными указателями признака пола в составных ТР. Отметим и строгую соотнесенность терминов для ниблингов (ДДР) по признаку пола альтера при безразличии к признаку пола коннектора. При четком разделении сиблингов родителей эго (ДРР) по полу отсутствует их противопоставление по относительному возрасту (старший/младший).

Еще одним примечательным и необычным свойством калмыцкой СТР является различение кровного и некровного родства (свойства) в группе наименований альтеров +1 поколения: 'мужской сиблинг матери’ (отношения кровного родства с эго) и 'супруг женского сиблинга матери’ (отношения внутреннего свойства); ‘женский сиблинг родителей’ (отношения кровного родства) и 'супруги мужских сиблингов родителей’ (отношения внутреннего свойства), в состав которых входит слово бергн, которым называют супругу старшего мужского сиблинга эго (0 поколение). К числу примечательных свойств СТР калмыков относится также использование одних и тех же лексических единиц (ач и зе) для обозначения ниблингов (-1 поколение) и детей детей (внука/внучки). Нейтрализация признака

${ }^{1}$ Для фиксации и описания терминологии родства в таблицах и в тексте статьи используется код Ю. И. Левина, широко применяемый в отечественной этнографии и социальной антропологии (подробнее см.: Левин, 1970; Крюков, 1972; Попов, 1982: 83-127).

Основные символы этого кода: Р - родитель; Д - дитя; С - супруг; Э - эго (говорящий); м, ж - детерминативы пола; «+» старший; «-»- младший. Так, РмРж (мужской родитель женского родителя) - отец матери, то есть дед по материнской стороне в русской СТР; +ДмРСж (старшее дитя мужского пола родителей супруги) -старший мужской сиблинг супруги, то есть старший брат жены, или старший шурин в русской СТР. 
поколения представляет собой нетипичное явление в СТР калмыков: обычно признаки поколения и относительного возраста имеют важное значение как для коннектора, так и для альтера. Исключением являются только термины $a x$ и эгч, которыми называют не только матрилатеральных сиблингов родителей эго (ДмРРж и ДжРРж), но и старших сиблингов эго (+ДР), что свидетельствует о наличии феномена скользящего счета поколений.

Характерной особенностью калмыцкой СТР, не находящей аналогий в СТР других монгольских народов, является бифуркативность, то есть различение пола коннектора для кузенов, выходящее на лексический уровень: названия патрилатеральных кузенов (ДДРРм) содержат слово үй, названия же матрилатеральных кузенов (ДДРРж) имеют в своем составе слово бөл.

В калмыцком языке существует также особая лексическая единица для обозначения матрилинейных родственников - наһцнр (мн. ч. с суффиксом - нр, характерное для названий лиц), которая используется для образования других составных ТР: наһu $a x$ - 'мужской сиблинг матери', наһц эгчи - 'женский сиблинг матери', наһu, бергн - 'супруга мужского сиблинга матери', наһu күргн ах - 'супруг женского сиблинга матери', наһц эк - ‘мать матери’, наһц эцк - 'отец матери’ (наряду с базовыми терминами см. табл. 1). Для номинации патрилатератов +2 поколения также используется составные ТР с

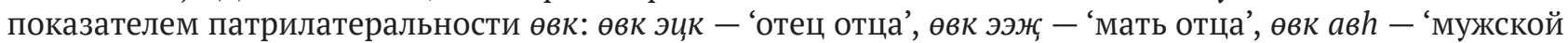
сиблинг отца отца’. Другими словами, сохраняется еще разделение на матри- и патрилатератов.

Еще одна важная черта СТР калмыков усматривается в соотношении ТР и используемых апеллятивов, заменяющих ТР в обращении. При этом не только сами по себе апеллятивы не соотносятся со словами $\mathrm{TP}$, но в области апеллятивов наблюдаются диалектные различия. Так, в дербетском говоре слово баав используется для обращения к альтерам мужского пола и имеет значения ‘отец, папа, дядя’, в то время как в торгутском говоре это же слово используется для обращения к женщинам: ‘мама, тётя’.

Для обозначения лиц, принадлежащих к одному поколению с эго, но находящихся в более отдаленных отношениях родства, нежели дети сиблингов родителей эго (кузены), в калмыцком языке существует сложная система наименований, и, очевидно, связанная с тем, что калмыцкий род - тохм (ст.-калм. toxom) - объединял родственников до 9-го колена (двоюродные, троюродные и т. д. до девятиюродных). Все эти ТР явно соотносятся в словообразовательном отношении с термином бөл 'матрилатеральный кузен', причем данные термины являются одинаковыми для говорящего мужчины (Эм) и говорящей женщины (Эж), то есть употребляются независимо от того, являются ли альтер и эго мужчиной или женщиной.

Для сравнительно-исторического изучения рассмотренных выше ТР существенно то, что термин зе, обозначающий одновременно ниблингов и внуков по женской линии (детей дочери) и представленный с тем же значением в других монгольских и некоторых тюркских языках (Номинханов, 1975: 67), был заимствован тунгусо-маньчжурскими языками, в частности, эвенкийским языком, и для эвенкийского ТP де [зэ:] в словаре дается неопределенный перевод ‘золовка' (Булатова, Бурыкин, 1999). По нашим данным, которые довольно хорошо согласуются с СТР других монгольских языков, в ТС лексема зе не используется, и причины такого семантического сдвига при заимствовании этого слова остаются не вполне понятными.

В целом же, СТР калмыков имеет все черты переходности от бифуркативно-линейного (группировка альтеров +1 поколения) к линейному типу (специфика номенклатуры родства в +2 , 0 и нисходящих поколениях). Кроме того, в СТР калмыков оказывается нейтрализованным противопоставление обобщенных ТР и ТС. Калмыцкое слово ург (ныне не употребляется), возможно, обладало значением 'родственник вообще', в то время как слово ураг у монголов и бурят имеет значение 'родственник по жене, свойственник'.

ТС калмыков имеют ряд весьма примечательных особенностей. Прежде всего, это необычная тернарная дифференциация обозначения супругов дочери, старшей сестры и младшей сестры: в большинстве СТР супруг дочери и супруг младшей сестры имеют единое обозначение, а русское слово зять обозначает и супруга дочери, и мужа сестры без возрастной дифференциации. Еще одна интересная деталь - это различение возраста коннектора (старший/младший) для обозначения зятя и невестки. Вообще признаком противопоставления ТС по возрасту альтера (старше альтера/младше альтера) является оппозиция слов хадм (различение пола альтера выражается второй частью наименования) и көвүн/күүкн - здесь во второй части наименования находится слово $\partial ү-$ 'младший сиблинг', не различающее пола в своем основном значении. Обращает на себя внимание и одинаковое обозначение сиблингов супругов вне зависимости от пола эго, но с различением их возраста относительно альтера. 
Примечательная особенность наименования супруги в калмыцком языке - это использование слова баавһа в значении 'жена', хотя такое словоупотребление имеет сниженную стилистическую окраску. В других монгольских языках, например, в современном монгольском, слово баавгай имеет только одно значение “медведь”, которое в калмыцком языке утрачено (калмыцкое название медведя аю заимствовано из тюркских языков). Принимая во внимание то, что северо-западные монголы (в том числе и ойраты) находились в контактах с тунгусоязычными народами, нельзя исключить того, что совмещение значений «медведь» и «жена» послужило основой для мифологических рассказов о браке человека и медведя в среде тунгусских народов, откуда они распространились по Средней и Восточной Сибири.

Характерное свойство составных ТС калмыков - это различение некоторых терминов по порядку следования лексических компонентов при тождестве самих этих компонентов. Сравним следующие наименования: $\partial \gamma$ көвүн - 'младший мужской сиблинг’ и көвұн $\partial \gamma$ - ‘младший мужской сиблинг супруга, деверь’, дү күүкн - ‘младший женский сиблинг’ и күүкн дү - ‘младший женский сиблинг супруга, золовка'.

Обращают на себя внимание разные названия невестки - бер и бергн (Бакаева, 2016: 254). По форме эти названия выглядят как производные от одного и того же корня, однако строго доказать это пока не представляется возможным. В материалах Ц.-Д. Номинханова (Номинханов, 1975: 69) приведено только слово бергн, для которого обнаружены параллели в других монгольских языках и приведены примеры из тюркских языков, очевидно, представляющие собой заимствования монгольского слова.

Что касается неразличения родителей супруга/супруги по признаку пола эго (тесть/свёкор и тёща/ свекровь), то аналогичным свойством обладают и ТС тунгусских народов - эвенов и эвенков (Бурыкин, 1998; Булатова, Бурыкин, 1999). Что касается дублетности обозначения матери супруга («свекровь») то слово эши в калмыцком и в письменном монгольском языке выглядит как заимствование из тюркских языков. Примечательно, что при совмещении значения 'мать супруга, тёща' и 'мать супруги, свекровь'

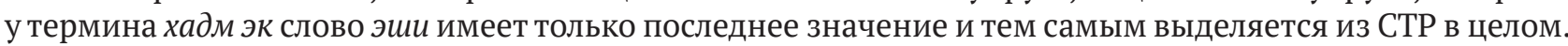

Яркой отличительной особенностью СТР калмыков в целом является моносемия подавляющего большинства ТР и ТС. Фактически многозначными являются только наименования для ниблингов и детей детей, а также названия родителей супругов.

Расхождения в лексическом составе слов, образующих СТР, между калмыцким языком и другими монгольскими языками немногочисленны. Помимо отмеченных выше употреблений слов баaвһa'жена' и эши - ‘свекровь', укажем, что калмыцкое өвк - ‘дед, дедушка', ‘предок, старец’, в других монгольских языках имеет только последнее значение, ср. современное монгольское өвөг - 'предок' (Номинханов, 1975: 69).

Довольно существенно отличается от соответствующей калмыцкой система наименований потомков в других монгольских языках. Так, если для СТР калмыков был характерен счет родства до 9 поколения в равной мере как по восходящей, так и по нисходящей линиям, то для СТР монголов и бурят отмечается счет только до +5 поколения по восходящей линии и -4 поколения по нисходящей линии. То есть, СТР калмыков выглядит как инновационная, однако нельзя исключать того, что TP, обозначающие родство в поколениях, отстоящих от эго далее чем на пять ступеней, у монголов и бурят утрачены, при этом в СТР бурят можно заметить следы восстановления счета поколений по сравнению с СТР монголов. Это заметно на примере материалов по нижнеудинскому диалекту бурятского языка, где в качестве основы для образования ТР в этих случаях выступают числительные, хотя само по себе созвучие некоторых ТР или их корней с корнями общемонгольских числительных может быть случайным - напомним, что в СТР калмыков термины для отсчета поколений не соотносятся с основами общемонгольских числительных. Наличие раздельных наименований для патри- и матрилатератов, или бифуркативность, оказывается универсальной особенностью СТР всех монгольских народов и может с большой степенью уверенности быть отнесено к позднейшему этапу общемонгольского состояния, поскольку ТР, обозначающие одинаковые классы родства по патри- и матрилиниям, выражены не разными лексическими единицами, а разными составными терминами, в которых дистинктором и одновременно показателем родства по матрилинии является слово паүас̌и и его закономерные отражения в отдельных языках.

Между калмыцким и неойратскими, монгольским и бурятским языками имеется довольно много различий и в составе ТС:

Монг. нөхөр, хар хүн, эр, эр нөхөр, бур. нүхэрынь, үбгэниинь, эрэнь, үбгэн, нүхэр (почтит.), зап. хурайха, булг. хуряахан - 'муж, супруг'. 
Монг. эхнэр, авгай, гэргий, бур. Һамган, эхнэр, нухэр һамган - 'супруга'.

Одно из трех названий для супруги - гэргий - является исторически общим с калмыцким, бурятское же слово һамган 'жена' не имеет соответствий в других языках.

Важным отличием ТС, бытующих у монголов и бурят, от калмыцких является наличие отдельного термина для жён двух братьев: монг. авьсан - 'супруга старшего мужского сиблинга по отношению к супруге младшего мужского сиблинга', вост.-бур. абьһан - 'невестка, супруга одного брата по отношению к супруге другого брата', письм.-монг. abisun - 'жена старшего брата по отношению к жене младшего брата’. У калмыков данный термин не отмечен. Еще одна лексическая особенность монгольской и бурятской СТР - это наличие отдельного термина для свойственницы в +1 поколении: монг. худгай - 'сватья', бур. худагы - 'сватья, кума', письм.-монг. хидиүиі - 'сватья'. У калмыков, как явствует из изложенного выше, наименования родителей супруга по отношению к родителям супруги (и наоборот) по полу не различаются.

Очевидно, что различия в составе СТР монголов, бурят и калмыков отражают разные, хотя и очень сходные, представления о СР как социальном феномене, которые подвергались дивергенции по отношению к исходному единому состоянию и к появлению языковых различий в выражении одних и тех же отношений родства.

\section{Тувинская терминология родства}

Компонентный анализ СТР тувинцев позволяет выделить те же дифференциальные переменные, как и в СТР калмыков, что свидетельствует об их историко-типологическом сходстве (см. табл. 2):

1. Генеалогическое поколение:

$1.1-+2$ поколение

$1.2-+1$ поколение

1.3 - 0 поколение

$1.4--1$ поколение

2. Пол альтера:

2.1 - мужской

2.2 - женский

3. Пол коннектора:

3.1 - мужской

3.2 - женский

4. Латеральность альтера:

4.1 - патрилатеральность

4.2 - матрилатеральность

5. Относительный возраст альтера:

5.1 - старше эго

5.2 - младше эго.

В СТР тувинцев можно отметить следующие особенности, сближающие ее с СТР калмыков и других ойратских народов. Это, прежде всего, неразличение пола младших сиблингов эго (-ДР). При этом лексема дуңма не имеет ярко выраженных параллелей в тюркских языках. Варианты этого слова с начальным звонким согласным $\partial$ - в других языках вообще не зафиксированы: вариант тунма отмечен в языке лебединских татар (алтайском), шорском, койбальском и хакасских диалектах (сагайском и качинском) (Радлов, 1905: стлб. 1435). Очевидно, данная лексема не является тюркской по происхождению. Она сравнима с монгольским словом $\partial y \gamma$ - 'младший сиблинг' (-ДР) и, возможно, заимствована тувинским (и хакасским) из какого-то ойратского языка, в котором имелась категория принадлежности в форме 1 л. ед. ч.

Показательно отсутствие в СТР тувинцев особых лексических единиц для обозначения потомков -2 поколения. Это же явление характерно для тунгусо-маньчжурских языков, однако оно нехарактерно для монгольских языков, в СТР которых признак поколения имеет намного большую значимость, а различение признака поколений на лексическом уровне (т. е. выражение поколения особой лексемой) охватывает как минимум 3 поколения по восходящей и нисходящей линиям. 
Табл. 2. Компонентный анализ СТР тувинцев

Tab. 2. Componential analysis of Tuvan system of kinship terms

\begin{tabular}{|c|c|c|c|c|c|c|}
\hline классы родства & десигнаты & \multicolumn{5}{|c|}{ сигнификаты } \\
\hline кырган-ача & РмP & 1.1 & 2.1 & - & - & - \\
\hline кырган-ава & РжР & 1.1 & 2.2 & - & - & - \\
\hline ире & РмРм $\left[\mathrm{PM}_{M}>2\right]=+Д м Р \mathrm{PM}$ & - & 2.1 & 3.1 & 4.1 & 5.1 \\
\hline акы & - ДмРРм = +ДмР & - & 2.1 & - & - & - \\
\hline ада (ата), ача & PM & 1.2 & 2.1 & - & 4.1 & - \\
\hline ие, ава & Рж & 1.2 & 2.2 & - & 4.2 & - \\
\hline када (эне) & +ДжРРм & 1.2 & 2.2 & 3.1 & 4.1 & 5.1 \\
\hline угба (ува) & -ДжРРм = +ДжР & - & 2.2 & - & - & 5.1 \\
\hline даай & ДмРРж & 1.2 & 2.1 & 3.2 & 4.2 & - \\
\hline даай-ава & ДжРРж & 1.2 & 2.2 & 3.2 & 4.2 & - \\
\hline дуңма & -ДР & 1.3 & - & - & - & 5.2 \\
\hline шаны & ДмДжРРж = ДДРР & 1.3 & - & - & - & - \\
\hline оглу, оол & Дм & 1.4 & 2.1 & - & - & - \\
\hline кыс (кызы), уруг & Дж & 1.4 & 2.2 & - & - & - \\
\hline чээн (дуңма) & ДДР & 1.4 & - & - & - & 5.2 \\
\hline
\end{tabular}

Слово уруг 'дочь' (Дж), очевидно, является эксклюзивным для тувинского языка и, скорее всего, заимствовано из монгольских языков, где слово ураг имеет значение 'родственник'. Сравнение его с древнетюркским уруг со значением 1. зерно, семя, косточка; 2. род, потомство (Древнетюркский словарь, 1969: 615) нам не кажется убедительным: в наши дни подобные сближения оставляют сомнение.

Противопоставление предков и потомков эго по патри- и матрилиниям в СТР тувинцев прослеживается только в виде особого наименования матери матери (РжРж) - даай-эне. Если рассматривать внутреннюю форму этого термина, то буквально он означает 'мать мужского сиблинга матери’. Возможно, он калькирован с ойратского наһц эк, наһц ээж - ‘мать матери’ у калмыков. На юго-восточном диалекте тувинского языка (эрзинском) данное слово употребляется.

В рассматриваемой СТР привлекают внимание обозначения альтеров +1 поколения. Здесь представляют интерес два явления. Во-первых, это противопоставление сиблингов родителей и их супругов, т. е. различение кровного родства и свойства в боковых линиях. Сходное явление отмечено и у калмыков. Во-вторых, в ТР тувинцев сохранено использование наименования старших сиблингов эго для обозначения младших сиблингов родителей эго: ср. акы - 'старший мужской сиблинг, младший мужской сиблинг отца' (-ДмРРм =+ДмР), угба - 'старший женский сиблинг, младший женский сиблинг отца' (-ДжРРм = +ДжР). В свою очередь, этот факт указывает на былую значимость признака возраста альтера для выражения этих отношений, однако в современном тувинском языке признак возраста альтера в этой группе ТР, очевидно, нейтрализован. Пол коннектора, соотносимый с родством по отцовской и по материнской линиям, при этом продолжает оставаться значимым. Следует отметить, что термин акы в качестве апеллятива используется для обращения и к брату отца, и к брату матери (т. е. замещает специализированную лексему даай (ДмРРж), что служит подтверждением к сказанному выше и одновременно указывает на ослабление противопоставленности мужской и женской линий в номинации мужских сиблингов родителей эго).

Логично предполагать, что для обозначения старших сиблингов родителей эго в тувинском языке использовались те же термины, что и для родственников +2 поколения. То, что у тувинцев сохраняются следы подобной СР, явствует и из соотносительности терминов даай-эне - 'мать матери' и даай-ава ‘женский сиблинг матери’: оба конечных компонента этих образований имеют значения: ‘мать’ и 'бабушка'.

Наименование детей сиблингов в тувинском языке по-разному представлено в разных источниках. С одной стороны, дети сиблингов без различия их пола и возраста и пола альтера обозначаются единым термином чээн, с другой стороны, в этой функции зафиксирован термин дунма - 'младший сиблинг'. 
Еще одна интересная деталь тувинской СТР - это использование основы даай, имеющей значение 'мужской сиблинг матери', для выражения понятия 'женский сиблинг матери' - даай-ава. Трудно не заметить здесь использование компонента ава ('мать') в составе сложного ТР. Сдвиг признака поколения и замещение его возрастным признаком, объединяющим два поколения $(0$ и +1$)$ старше эго по возрасту, соотносится с некоторыми явлениями в терминах свойства. Это многозначность слов каты - 'отец супруги'; старший мужской сиблинг супруги', кат-ие - 'мать супруги, старший женский сиблинг супруги', бег, бээ - 'отец супруга; 'старший мужской сиблинг супруга', кунчуг, кунчуу - 'мать супруга; старший женский сиблинг супруга'.

Не может остаться без внимания и сходство термина ача - 'отец' с монгольским обозначением потомка в -2 поколении: ср. калм. ачнр, ст.-калм. асі (ед. ч.) - ‘дети сына’. Впрочем, нельзя исключать и того, что данная форма представляет собой монгольское слово со значением “отец” (калм. эцке) с измененной огласовкой. В. В. Радлов предположил, что форма ача может восходить к праформе *атача (Радлов, 1888: стлб. 502), однако это все же маловероятно.

Самая примечательная особенность номенклатуры родства тувинцев - это большое своеобразие ТС и, прежде всего - неразличение свойства по признаку поколения: ТР для отца/матери и для старших сиблингов супруга или супруги являются одними и теми же, но они противопоставлены отдельным TP для младшего сиблинга супруга/супруги. Другая особенность ТС тувинцев - неразличение пола младшего сиблинга супруга/супруги. Важно отметить и то, что некоторые ТР используются и как ТС: чеңге и чаава, очевидно, выступающие как синонимы.

В сравнительно-историческом отношении заслуживают внимания также тувинские ТС, содержащие компонент кат-: каты - 'отец жены', каты, кадайның акызы - 'старший мужской сиблинг жены', кат-ие - 'мать жены', 'старший женский сиблинг жены'. Этот компонент является тождественным исторически алтайскому слову кайны, обозначающим свойственников, и оба слова соотносятся с монгольским хadum, обозначающим некровных родственников вообще, ср. также калм. хадм эцк 'отец жены/мужа', ст.-калм. хаdam 'родня мужа или жены', калм. хадм эк - 'мать жены/мужа', хадм $a x$ - 'старший мужской сиблинг жены, хадм эгч - 'старший женский сиблинг жены', хадм $а x$ - 'старший мужской сиблинг мужа', хадм эгч - 'старший женский сиблинг мужа'.

Помимо названий родственников мужа для (Эж), к монгольским заимствованиям могут быть отнесены также слова куда - 'сват' и кудагай - 'сватья', при этом только форма кудагай, отмеченная также в хакасском и якутском языках (ср. хакасск. худаңай, якут. ходогой 'сватья'), указывает на то, что данные слова заимствованы тюркскими языками из монгольских языков, а не наоборот. Аналогичным образом термин бажа - 'свояк', который также является тюрко-монгольским, отмечается не только в тувинском, но и в других тюркских языках.

Исследование СТР калмыков и тувинцев подтверждает, что термины свойства обладают большей устойчивостью и лучшей сохраняемостью, нежели термины кровного родства. Поэтому, едва ли есть основания объяснять факт сходства тюркских и монгольских терминов свойства как результат заимствования их монголами у тюрок. Кроме того, имеется еще одно обстоятельство, заметно снижающее достоверность объяснения этих сходств как заимствований. Если считать особенности внешнего облика монгольских ТР как заимствования этих слов из разных тюркских языковых групп или в разные исторические периоды, то получается, что слова «зять», «родственники мужа» и «ниблинг», заимствованы либо из тюркских языков, принадлежащих к трем разным группам, либо в три разные исторические эпохи. Тюркский межзубной согласный ${ }^{*} D$, который встречается в двух словах из трех, имеет разные отражения ( $r$ и $d)$, а в тех языках, где на месте начального $j$ - встречается звонкий среднеязычный согласный 3 , межзубной согласный * $D$ отражается только в виде $j$, но не как $d$ и не сонант $r$. Однако все названные слова принадлежат к одной тематической группе и едва ли они могли быть заимствованы монгольскими языками из тюркских языков в разное время или быть воспринятыми из трех разных тюркских языков-источников, столь значительно различающихся между собой, как различаются современные киргизский, тувинский и чувашский языки.

Изучение региональных вариантов СТР тувинцев показывает значительную степень влияния монгольской СТР на тувинскую (Кара-оол, 2000, 2001 ab; Айыжы, Конгу, 2013ab), что, однако, характерно для отдельных групп тувинцев, испытывающих на себе позднейшее монгольское влияние. Ср. тув. угбай ('сестра') - эгчи (монг. эгч) (Айыжы, Конгу, 2013a: 38; 2013b: 25), много монгольских ТР параллельно с тувинскими употребляют тувинцы-эрзинцы (Кара-оол, 2001b: 251). 


\section{Заключение}

В итоге мы можем сделать два весьма важных вывода.

Во-первых, получается, что объяснение наблюдаемых лексических сходств тюркских и монгольских языков исключительно как контактных явлений в свете фактов истории самих тюркских языков имеет на несколько порядков меньшую вероятность, чем объяснение тех же сходств как следствие генетического родства алтайских языков при наличии в них некоторого количества перекрестных заимствований. Невозможно поверить в то, что монгольские ТР, составляющие довольно компактную лексическую группу, были заимствованы из тюркских языков трех разных групп или в три разные исторические эпохи, даже если такие построения и укладываются в представления о «формальной» истории тюркских языков в плане соответствия описываемых фактов какой-то языковой реальности или отвечают чьей-либо концепции исторической фонетики тюркских языков - общая картина взаимодействия языков в этом случае становится неправдоподобной.

Во-вторых, если вести речь об изучении ареальных связей тюркских языков на уровне их взаимодействия с языками иных групп, то надо признать, что при таком подходе конкретные результаты для какого-то одного отдельно взятого языка - в данном случае для тувинского языка, где монгольское влияние до недавнего времени было весьма значительным - должны оцениваться как весьма невыразительные, а для группы тюркских языков в целом они представляются слишком неопределенными. Для такой языковой группы, как тюркские языки в целом, выводы ареального характера на основе идеи генетической изолированности этих языков от других алтайских языков оказываются частью довольно тривиальными, частью попросту неверифицируемыми.

\section{СПИСОК ЛИТЕРАТУРЫ}

Айыжы, Е. В., Конгу, А. А. (2013а) Родовые группы тувинцев Кобдоского аймака Монголии на современном этапе (по материалам полевых исследований) // Вестник Калмыцкого института гуманитарных исследований РАН. № 1. С. 36-40.

Айыжы, Е. В., Конгу, А. А. (2013b) Тувинцы Синьцзян-Уйгурского автономного района Китая (по материалам этнографической экспедиции в Синьцзян-Уйгурский, автономный район Китая) // Вестник Кемеровского государственного университета. № 1 (3). С. $23-27$.

Бакаева, Э. П. (2014) Об обозначении возрастных категорий в культуре ойратов и калмыков // Вестник Калмыцкого института гуманитарных исследований РАН. № 4. С. 89-95.

Бакаева, Э. П. (2016) Лексика, связанная с обозначением возрастных категорий и социального статуса человека в культуре ойратов и калмыков // Трансграничная культура: очерки сравнительносопоставительного исследования традиций западных монголов и калмыков : монография / Э. П. Бакаева, К. В. Орлова, Д. Н. Музраева и др. Элиста : КалмНЦ РАН. 456 с. С. 247-256.

Бембеев, В. Ш. (2004) Ойраты. Ойрат-калмыки. Калмыки : в 2-х кн. Элиста : АПП «Джангар». Кн. 1. 496 c.

Биче-оол, С. М. (2001) Система родства у тувинцев // Гуманитарные исследования в Туве : сб. научных статей / отв. ред. К. А. Бичелдей и др. М. : Изд-во РУДН. 331[1] с. С. 190-202.

Биче-оол С. М. (2018) Традиционные брачно-семейные отношения у тувинцев и их трансформация в советский период. Абакан : Журналист. 125 с.

Большой академический монгольско-русский словарь (2001-2002) : в 4-х т. / под общ. ред. А. Лувсандэндэва и Ц. Цэдэндамбы. М. : Academia. 487+439+507+532 с.

Булатова, Н. Я, Бурыкин, А. А. (1999) Система терминов родства эвенков (предварительные материалы к описанию) // Алгебра родства / отв. ред. В. А. Попов. Вып. 3. СПб. : МАЭ РАН. 288 с. С. $267-277$.

Бурыкин, А. А. (1998) Семантическая структура эвенских терминов родства и свойства // Алгебра родства / отв. ред. В. А. Попов. Вып. 2. СПб. : МАЭ РАН. 288 с. С. 155-166.

Бурыкин, А. А., Летягина, Н. И. (1999) Терминология родства тувинцев в сравнении с терминами родства других тюркских народов Южной Сибири // Алгебра родства / отв. ред. В. А. Попов. Вып. 4. СПб. : МАЭ РАН. 288 с. С. 179-196.

Древнетюркский словарь (1969) 2-е изд. / Д. М. Насилов, В. М. Наделяев, А. М. Щербак и др. Астана : Гылым баспасы. 760 с. 
Калмыцко-русский словарь (1977) / отв. ред. Б. Д. Муниев. М. : Русский язык. 768 с.

Кара-оол, Л. С. (2000) О некоторых особенностях терминов родства в кара-хольском говоре западного диалекта тувинского языка // Становление и развитие науки в Туве. Материалы международной конференции, посв. 70-летию тувинской письменности / отв. ред. Х. Д.-Н. Ооржак и др. Кызыл : ТГУ. 135 с.: ил. С. $83-85$.

Кара-оол, Л. С. (2001a) О некоторых особенностях терминов родства из языка ховдских тувинцев // Тезисы докладов V Международной научной конференции «Природные условия, история и культура Западной Монголии и сопредельных регионов» (20-24 сентября 2001 г., г. Ховд, Монголия) / отв. ред. Э. В. Галажинский, Ж. Янжмаа и др. Томск : Изд-во ТГУ. 293 с. С. 200-201.

Кара-оол, Л. С. (2001b) О некоторых особенностях функционирования терминов родства у тувинцевэрзинцев // Алгебра родства. Родство. Система родства. Система терминов родства / отв. ред. В. А. Попов. Вып. 7. СПб. : МАЭ РАН. 288 с. С. 248-254.

Кара-оол, Л. С. (2006) Термины родства и свойства в тувинском языке. Кызыл : РИО ТувГУ. 252 с.

Корсункиев, Ц.К. (1977) О терминах родства у калмыков // Культура и быт калмыков: этнографические исследования / отв. ред. А. Г. Митиров. Элиста : КНИИЯЛИ. 124 с. С. 59-72.

Крюков, М. В. (1972) Система родства китайцев. М. : Наука ; ГРВЛ. 328 с.

Кузнецов, А. М. (1971) О применении метода компонентного анализа в лексике // Синхронносопоставительный анализ языков разных систем / отв. ред. Э. А. Макаев. М. : Наука. 279 с. С. 257-268.

Левин, Ю. И. (1970) Об описании системы терминов родства // Советская этнография. № 4. С. 18-30.

Музраева, Д. Н. (2016) Лексические материалы к изучению традиционного быта ойратов Западной Монголии // Трансграничная культура: очерки сравнительно-сопоставительного исследования традиций западных монголов и калмыков : монография / Э. П. Бакаева, К. В. Орлова, Д. Н. Музраева и др. Элиста : КалмНЦ РАН. 456 с. С. 232-247.

Мулаева, Н. М. (2016) Термины родства и свойства в толковом словаре языка калмыцкого героического эпоса «Джангар» // Вестник Калмыцкого института гуманитарных исследований РАН. № 1. С. 189201. DOI 10.22162/2075-7794-2016-23-1-189-201

Номинханов, Ц.-Д. (1958) Термины родства в тюрко-монгольских языках // Вопросы истории и диалектологии казахского языка / отв. ред. Н. Т. Сауранбаев. Вып. 1. Алма-Ата : Изд-во АН КазССР. 215 с. C. $42-48$.

Номинханов, Ц.-Д. (1975) Материалы к изучению истории калмыцкого языка. М. : Наука, ГРВЛ. 324 с.

Омакаева, Э. У., Бурыкин, А. А. (1999) Термины родства и свойства калмыков // Алгебра родства / отв. ред. В. А. Попов. ВыП. 4. СПб. : МАЭ РАН. 288 с. С. 212-221.

Омакаева, Э. У., Бурыкин, А. А. (2001) Термины родства и свойства монголов и бурят // Алгебра родства / отв. ред. В. А. Попов. Вып. 7. СПб. : МАЭ РАН. 288 с. С. 240-247.

Омакаева Э. У., Бурыкин А. А. (2007) Система терминов родства и свойства у калмыков (в сравнении с системами терминов родства монголов и бурят) // Монголоведение. № 4. С. 41-58.

Очирова, В. С., Омакаева, Э. У. (2014) Номинации лиц мужского пола по степени родства в калмыцком языке: на материале песенных текстов // Вестник Калмыцкого института гуманитарных исследований РАН. № 1. С. 42-46.

Попов, В. А. (1979) Опыт компонентного анализа систем терминов родства ашанти и фанти // Этнокультурные процессы в современных и традиционных обществах / отв. ред. Г. А. Аксянова, И. И. Крупник, О. Б. Наумова. М. : Институт этнографии АН СССР. 184 с. С. 118-129.

Попов, В. А. (1982) Ашантийцы в XIX в. : Опыт этносоциологического исследования. М. : Наука, ГРВЛ. $176 \mathrm{c.}$

Радлов, В. В. (1888) Опыт словаря тюркских наречий : в 4 т. СПб. : Типография АН. Т. І. Гласные. XVIII с., 1914 стлб.

Радлов, В. В. (1905) Опыт словаря тюркских наречий : в 4 т. СПб. : Типография АН. Т. III. 2203 стлб.

Русско-калмыцкий словарь (1964) / под ред. И. К. Илишкина. М. : Советская Энциклопедия. 803 с.

Степанофф, Ш. (2009) Метаморфозы родства у тувинцев // Этнографическое обозрение. № 4. C. $129-145$. 
Тувинско-русский словарь (1968) / отв. ред. Э. Р. Тенишев. М. : Советская энциклопедия. 646 с.

Членов, М. А. (1972) Формальные методы изучения систем родства в современной американской этнографии // Этнологические исследования за рубежом / отв. ред. Ю. В. Бромлей. М. : Наука. 232 с. С. 143-169.

Шалык Ч. С. (2018) Об истории изучения терминов родства и свойства в тувинском языке [Электронный ресурс] // Научно-практический электронный журнал «Аллея Науки». Т. 1. № 2 (18). C. 752-757. URL: https://www.alley-science.ru/domains_data/files/February2-181/OB\%20ISTORII\%20 IZUChENIYa\%20TERMINOV\%20RODSTVA\%20I\%20SVOYSTVA.pdf (дата обращения: 16.05.2019). 1218 p.

Lessing, F. D. (1960) Mongolian-English Dictionary. Berkeley-Los Angeles : University of California Press. Дата поступления: 02.09.2019 2.

\section{REFERENCES}

Aiyzhy, E. V. and Kongu, A. A. (2013a) Rodovye gruppy tuvintsev Kobdoskogo aimaka Mongolii na sovremennom etape (po materialam polevykh issledovanii) [Tuvan clans of Khovd Province (Mongolia) at the present stage (a field study)]. Bulletin of the Kalmyk Institute for Humanities of the Russian Academy of Sciences (Oriental Studies), no. 1, pp. 36-40. (In Russ.).

Aiyzhy, E. V. and Kongu, A. A. (2013b) Tuvintsy Sin'tszyan-Uigurskogo avtonomnogo raiona Kitaya (po materialam etnograficheskoi ekspeditsii v Sin'tszyan-Uigurskii, avtonomnyi raion Kitaya) [The Tuvans of Xinjiang Uygur Autonomous Region of China (the materials of an ethnographic expedition to Xinjiang Uygur Autonomous Region of China)]. Vestnik Kemerovskogo gosudarstvennogo universiteta, no. 1(3), pp. 23-27. (In Russ.).

Bakaeva, E. P. (2014) Ob oboznachenii vozrastnykh kategorii v kul'ture oiratov i kalmykov [To the issue of denoting age categories in the Oirat and Kalmyk cultures]. Bulletin of the Kalmyk Institute for Humanities of the Russian Academy of Sciences (Oriental Studies), no. 4, pp. 89-95. (In Russ.).

Bakaeva, E. P. (2016) Leksika, svyazannaya s oboznacheniem vozrastnykh kategorii i sotsial'nogo statusa cheloveka v kul'ture oiratov i kalmykov [Words serving to denote age categories and individual social status in cultures of the Oirats and Kalmyks]. In: Transgranichnaya kul'tura: ocherki sravnitel'no-sopostavitel'nogo issledovaniya traditsii zapadnykh mongolov i kalmykov [Cross-border culture: comparative research sketches of traditions of the western Mongols and Kalmyks] / ed. by E. P. Bakaeva et al. Elista, Kalmyk Scientific Center of RAS. 456 p. Pp. 247-256. (In Russ.).

Bembeev, V. Sh. (2004) Oiraty. Oirat-kalmyki. Kalmyki [Oirats. Oirat-Kalmyks. Kalmyks]. In 2 vols. Elista, Dzhangar. Vol. 1.496 p. (In Russ.).

Biche-ool, S. M. (2001) Sistema rodstva u tuvintsev [Kinship system of the Tuvans]. In: Gumanitarnye issledovaniya $v$ Tuve [Humanities research in Tuva]. Coll. articles. Ed. by K. A. Bicheldey et al. Moscow, RUDN University Press. 331[1] p. Pp. 190-202. (In Russ.).

Biche-ool, S. M. (2018) Traditsionnye brachno-semeinye otnosheniya u tuvintsev $i$ ikh transformatsiya $v$ sovetskii period [Traditional matrimonial and family relations among the Tuvans and their transformation during the Soviet era]. Abakan, Zhurnalist. 125 p. (In Russ.).

Bol'shoi akademicheskii mongol'sko-russkii slovar' [Unabridged Academic Mongolian-Russian Dictionary] (2001-2002) : in 4 vols. Ed. by A. Luvsandedev and Ts. Tsedendamba. Moscow, Academia Publ. Vol. 1, 487 p. Vol. 2, 439 p. Vol. 3, 507 p. Vol. 4, 532 p. (In Russ. and Mong.).

Bulatova, N. Ya. and Burykin, A. A. (1999) Sistema terminov rodstva evenkov (predvaritel'nye materialy k opisaniyu) [Kinship terminology system of the Evenks (preliminary descriptions)]. In: Algebra rodstva [Algebra of kinship]. Issue 3. Ed. by V. A. Popov. St. Petersburg, Museum of Anthropology and Ethnography of RAS. 288 p. Pp. 267-277. (In Russ.).

Burykin, A. A. (1998) Semanticheskaya struktura evenskikh terminov rodstva i svoistva [The semantic structure of Even kinship and affinity]. In: Algebra rodstva [Algebra of kinship]. Issue 2. Ed. by V. A. Popov. St. Petersburg, Museum of Anthropology and Ethnography of RAS. 288 p. Pp. 155-166. (In Russ.).

Burykin, A. A. and Letyagina, N. I. (1999) Terminologiya rodstva tuvintsev v sravnenii s terminami rodstva drugikh tyurkskikh narodov Yuzhnoi Sibiri [Tuvan kinship terminology in comparison with kinship terms of 
other South Siberian Turks]. In: Algebra rodstva [Algebra of kinship]. Issue 4. Ed. by V. A. Popov. St. Petersburg, Museum of Anthropology and Ethnography of RAS. 288 p. Pp. 179-196. (In Russ.).

Drevnetyurkskii slovar' [Dictionary of Old Turkic] (1969). 2nd ed. Comp. by D. M. Nasilov, V. M. Nadelyaev, A. M. Shcherbak et al. Astana, Gylym. 760 p. (In Russ.).

Kalmytsko-russkii slovar' [Kalmyk-Russian dictionary] (1977). Ed. by B. D. Muniev. Moscow, Russkiji yazyk. 768 p. (In Kalm. and Russ.).

Kara-ool, L. S. (2000) O nekotorykh osobennostyakh terminov rodstva v kara-khol'skom govore zapadnogo dialekta tuvinskogo yazyka [On some peculiarities of kinship terms in the Kara-Khol branch of the western Tuvan dialect]. In: Stanovlenie i razvitie nauki v Tuve [Formation and development of science in Tuva]: Proceedings of the international conference dedicated to the 70th anniversary of the Tuvan written language. Ed. by Kh. D.-N. Oorzhak et al. Kyzyl, Tuvan State University. 135 p. Pp. 83-85. (In Russ.).

Kara-ool, L. S. (2001a) O nekotorykh osobennostyakh terminov rodstva iz yazyka khovdskikh tuvintsev [On some features of kinship terms from the language of Khovd Tuvans]. In: Prirodnye usloviya, istoriya $i$ kul'tura Zapadnoi Mongolii i sopredel'nykh regionov [Natural conditions, history and culture of Western Mongolia and adjacent regions]: Abstracts of reports of the 5th International scientific conference. Ed. By E. V. Galazhinsky, Zh. Yanzhmaa and others. Tomsk, Tomsk State University. 293 p. Pp. 200-201. (In Russ.).

Kara-ool, L. S. (2001b) O nekotorykh osobennostyakh funktsionirovaniya terminov rodstva u tuvintseverzintsev [On some features of functioning of kinship terms among Erzin Tuvans]. In: Algebra rodstva. Rodstvo. Sistema rodstva. Sistema terminov rodstva [Algebra of kinship. Kinship. Kinship system. System of kinship terms]. Issue 7. Ed. by V. A. Popov. St. Petersburg, Museum of Anthropology and Ethnography of RAS. 288 p. Pp. 248-254. (In Russ.).

Kara-ool, L. S. (2006) Terminy rodstva i svoistva $v$ tuvinskom yazyke [Kinship and affinity terms in the Tuvan language]. Kyzyl, Tuvan State University. 252 p. (In Russ.).

Korsunkiev, C. K. (1977) O terminakh rodstva u kalmykov [On kinship terms of the Kalmyks]. In: Kul'tura i byt kalmykov: etnograficheskie issledovaniya [Culture and life of Kalmyks: ethnographic studies]. Ed. by A. G. Mitirov. Elista, KNIIYaLI. 124 p. Pp. 59-72. (In Russ.).

Kryukov, M. V. (1972) Sistema rodstva kitaitsev [Chinese kinship system]. Moscow, Nauka, GRVL. 328 p. (In Russ.).

Kuznetsov, A. M. (1971) O primenenii metoda komponentnogo analiza v leksike [On application of the component analysis method of in vocabulary studies]. In: Sinkhronno-sopostavitel'nyi analiz yazykov raznykh sistem [Synchronous-comparative analysis of structurally different languages]. Ed. by E. A. Makaev. Moscow, Nauka. 279 p. Pp. 257-268. (In Russ.).

Levin, Yu. I. (1970) Ob opisanii sistemy termonov rodstva [On the description of the system of kinship terms]. Sovetskaya etnografia, no. 4, pp. 18-30. (In Russ.).

Mulaeva, N. M. (2016) Terminy rodstva i svoistva v tolkovom slovare yazyka kalmytskogo geroicheskogo eposa «Dzhangar» [Terms of kinship and affinity in the dictionary of the language of the Kalmyk heroic epic 'Dzhangar']. Oriental Studies, no. 1, pp. 189-201. (In Russ.). DOI 10.22162/2075-7794-2016-23-1-189-201

Muzraeva, D. N. (2016) Leksicheskie materialy k izucheniyu traditsionnogo byta oiratov Zapadnoi Mongolii [Oirats of Western Mongolia: lexical materials for studies of the traditional household activities]. In: Transgranichnaya kul'tura: ocherki sravnitel'no-sopostavitel'nogo issledovaniya traditsii zapadnykh mongolov $i$ kalmykov [Cross-border culture: comparative research sketches of traditions of the western Mongols and Kalmyks] / E. P. Bakaeva, K. V. Orlova, D. N. Muzraeva et al. Elista, Kalmyk Scientific Center of RAS. 456 p. Pp. 232-247. (In Russ.).

Nominhanov, Ts.-D. (1958) Terminy rodstva v tyurko-mongol'skih yazykah [Kinship terms in the TurkoMongolic languages]. In: Voprosy istorii i dialektologii kazahskogo yazyka [Questions of history and dialectology of the Kazakh language]. Ed. by N. T. Sauranbaev. Alma-Ata, Academy of Sciences of the Kazakh SSR. Issue 1. 215 p. Pp. 42-48. (In Russ.).

Nominhanov, Ts.-D. (1975) Materialy k izucheniyu istorii kalmytskogo yazyka [Materials to historical studies of the Kalmyk language]. Moscow, Nauka, GRVL. 324 p. (In Russ.).

Omakaeva, E. U. and Burykin, A. A. (1999) Terminy rodstva i svoistva kalmykov [Kinship and in-law terms of the Kalmyks]. In: Algebra rodstva [Algebra of kinship]. Issue 4. Ed. by V. A. Popov. St. Petersburg, Museum of Anthropology and Ethnography of RAS. 288 p. Pp. 212-221. (In Russ.). 
Omakaeva, E. U. and Burykin, A. A. (2001) Terminy rodstva i svoistva mongolov i buryat [Kinship and affinity terms of the Mongols and Buryats]. In: Algebra rodstva [Algebra of kinship]. Issue 7. Ed. by V. A. Popov. St. Petersburg, Museum of Anthropology and Ethnography of RAS. 288 p. Pp. 240-247. (In Russ.).

Omakaeva, E. U. and Burykin, A. A. (2007) Sistema terminov rodstva i svoistva u kalmykov (v sravnenii $\mathrm{s}$ sistemami terminov rodstva mongolov i buryat) [System of kinship and affinity terms of the Kalmyks (in comparison with those of the Mongols and Buryats)]. Mongolovedenie, no. 4, pp. 41-58. (In Russ.).

Ochirova, V.S. and Omakaeva E.U. (2014) Nominatsii lits muzhskogo pola po stepeni rodstva v kalmytskom yazyke: na materiale pesennykh tekstov [Nomination of males by degree of kinship in the Kalmyk language: a case study of song texts]. Bulletin of the Kalmyk Institute for Humanities of the Russian Academy of Sciences (Oriental Studies), no. 1, pp. 42-46. (In Russ.).

Popov, V. A. (1979) Opyt komponentnogo analiza sistem termonov rodstva ashanti i fanti [Ashanti and Fante kinship terminology systems: experience of component analysis]. In: Etnokul'turnye protsessy $v$ sovremennykh i traditsionnykh obshchestvakh [Ethnocultural processes in modern and traditional societies]. Ed. by G. A. Aksyanova, I. I. Krupnik and O. B. Naumova. Moscow, Institute of Ethnography, USSR Acad. of Sc. 184 p. Pp. 118-129. (In Russ.).

Popov, V. A. (1982) Ashantiitsy v XIX v.: Opyt etnosotsiologicheskogo issledovaniya [The Ashanti in the 19th century: experience of ethno-sociological research]. Moscow, Nauka, GRVL. 176 p. (In Russ.).

Radlov, V. V. (1888) Opyt slovarya tyurkskih narechij [Experience the dictionary of Turkic dialects]. In 4 vol. St. Petersburg, Typography of the Academy of Sciences. Vol. I. Glasnye [Vowels]. XVIII p.+1914 columns. (In Turkic).

Radlov, V. V. (1905) Opyt slovarya tyurkskikh narechii [Experience the dictionary of Turkic dialects]. In 4 vols. St. Petersburg, Imperial Acad. of Sc. Vol. III. 2203 columns. (In Turkic).

Russko-kalmytskii slovar [Russian-Kalmyk dictionary] (1964). Ed. by I. K. Ilishkin. Moscow, Sovetskaya Entsyklopedia. 803 p. (In Russ. and Kalm.).

Stepanoff, Sh. (2009) Metamorfozy rodstva u tuvintsev [Metamorphoses of kinship among the Tuvans]. Etnograficheskoe obozrenie, no. 4, pp. 129-145. (In Russ.).

Tuvinsko-russkii slovar' [Tuvan-Russian dictionary] (1968). Ed. by E. R. Tenishev. Moscow, Sovetskaya Entsyklopedia. 646 p. (In Tuvan and Russ.)

Chlenov, M. A. (1972) Formal'nye metody izucheniya sistem rodstva v sovremennoi amerikanskoi etnografii [Formal methods applied by modern American ethnography to investigate kinship systems]. In: Etnologicheskie issledovaniya za rubezhom [Ethnological studies abroad]. Ed. by Yu. V. Bromlei. Moscow, Nauka. 232 p. Pp. 143-169. (In Russ.).

Shalyk, Ch. S. (2018) Ob istorii izucheniya terminov rodstva i svoistva v tuvinskom yazyke [Studies of kinship and in-law terms in the Tuvan language: history revisited]. Nauchno-prakticheskij elektronnyj zhurnal «Alleya Nauki», vol. 1, no. 2 (18), pp.752-757. [online] Available at: https://www.alley-science.ru/domains_data/ files/February2-181/OB\%20ISTORII\%20IZUChENIYa\%20TERMINOV\%20RODSTVA\%20I\%20SVOYSTVA.pdf (access date: 16.05.19). (In Russ.).

Lessing, F. D. (1960) Mongolian-English Dictionary. Berkeley-Los Angeles, University of California Press. 1218 p. (In Eng.).

Submission date: 02.09.2019. 